\title{
Characterization of cellular uptake and toxicity of aminosilane-coated iron oxide nanoparticles with different charges in central nervous system- relevant cell culture models
}

\author{
This article was published in the following Dove Press journal: \\ International Journal of Nanomedicine \\ 6 March 2013 \\ Number of times this article has been viewed
}

\author{
Zhizhi Sun' \\ Vinith Yathindranath ${ }^{2}$ \\ Matthew Worden ${ }^{3}$ \\ James A Thliveris ${ }^{4}$ \\ Stephanie Chu' \\ Fiona E Parkinson' \\ Torsten Hegmann ${ }^{1-3}$ \\ Donald W Miller' \\ 'Department of Pharmacology \\ and Therapeutics, ${ }^{2}$ Department of \\ Chemistry, University of Manitoba, \\ Winnipeg, Manitoba, Canada; \\ ${ }^{3}$ Chemical Physics Interdisciplinary \\ Program, Liquid Crystal Institute, \\ Kent State University, Kent, OH, USA; \\ ${ }^{4}$ Department of Human Anatomy and \\ Cell Science, University of Manitoba, \\ Winnipeg, Manitoba, Canada
}

\begin{abstract}
Background: Aminosilane-coated iron oxide nanoparticles (AmS-IONPs) have been widely used in constructing complex and multifunctional drug delivery systems. However, the biocompatibility and uptake characteristics of AmS-IONPs in central nervous system (CNS)relevant cells are unknown. The purpose of this study was to determine the effect of surface charge and magnetic field on toxicity and uptake of AmS-IONPs in CNS-relevant cell types.

Methods: The toxicity and uptake profile of positively charged AmS-IONPs and negatively charged $\mathrm{COOH}-\mathrm{AmS}$-IONPs of similar size were examined using a mouse brain microvessel endothelial cell line (bEnd.3) and primary cultured mouse astrocytes and neurons. Cell accumulation of IONPs was examined using the ferrozine assay, and cytotoxicity was assessed by the 3-(4,5-dimethylthiazol-2-yl)-2,5-diphenyltetrazolium bromide (MTT) assay.
\end{abstract}

Results: No toxicity was observed in bEnd. 3 cells at concentrations up to $200 \mu \mathrm{g} / \mathrm{mL}$ for either AmS-IONPs or COOH-AmS-IONPs. AmS-IONPs at concentrations above $200 \mu \mathrm{g} / \mathrm{mL}$ reduced neuron viability by $50 \%$ in the presence or absence of a magnetic field, while only $20 \%$ reductions in viability were observed with $\mathrm{COOH}-\mathrm{AmS}-\mathrm{IONPs}$. Similar concentrations of AmS-IONPs in astrocyte cultures reduced viability to $75 \%$ but only in the presence of a magnetic field, while exposure to $\mathrm{COOH}-\mathrm{AmS}-\mathrm{IONPs}$ reduced viability to $65 \%$ and $35 \%$ in the absence and presence of a magnetic field, respectively. Cellular accumulation of AmS-IONPs was greater in all cell types examined compared to $\mathrm{COOH}-\mathrm{AmS}-\mathrm{IONPs}$. Rank order of cellular uptake for AmS-IONPs was astrocytes $>$ bEnd.3 $>$ neurons. Accumulation of COOH-AmS-IONPs was minimal and similar in magnitude in different cell types. Magnetic field exposure enhanced cellular accumulation of both AmS- and COOH-AmS-IONPs.

Conclusion: Both IONP compositions were nontoxic at concentrations below $100 \mu \mathrm{g} / \mathrm{mL}$ in all cell types examined. At doses above $100 \mu \mathrm{g} / \mathrm{mL}$, neurons were more sensitive to AmS-IONPs, whereas astrocytes were more vulnerable toward COOH-AmS-IONPs. Toxicity appears to be dependent on the surface coating as opposed to the amount of iron-oxide present in the cell.

Keywords: drug delivery, magnetic nanoparticles, magnetic field, biocompatibility, cellular accumulation, brain

Iron oxide nanoparticles (IONPs) have been proposed for various biomedical applications targeting the brain, including cell labeling, ${ }^{1}$ cancer hyperthermia, ${ }^{2}$ and drug delivery. ${ }^{3}$ Due to their superparamagnetic properties, IONPs as potential drug carriers offer the additional advantages of being traceable within the body, using magnetic resonance imaging (MRI), as well as being targetable to selected tissues with application of magnetic fields. The latter property is of particular interest
Correspondence: Donald W Miller Department of Pharmacology and Therapeutics, 753 McDermot Avenue, University of Manitoba, Winnipeg, Manitoba, Canada R3E 0T6

Tel +l 2047893278

Fax +I 2047893932

Email miller5@cc.umanitoba.ca 
to overcome obstacles, such as off-target toxicity due to accumulation of nanoparticles in nontarget tissue and suboptimal therapeutic response due to inadequate concentrations of nanoparticles at the target site. However, a major liability in using uncoated IONPs is the tendency for aggregation when placed in an aqueous environment. Furthermore, these aggregation problems observed with uncoated IONPs are accentuated in the presence of an external magnetic field. ${ }^{4}$ In addition, uncoated IONPs lack functional groups on the surface of the nanoparticles that limit the extent to which surface modifications can be made to enhance cellular uptake or colloidal drug stability. Thus, surface modification of IONPs is necessary to prevent aggregation and allow the addition of specific functionalities to IONPs, including polymer coating, tissue targeting vectors, and fluorescent dye.

As central nervous system (CNS) applications for IONP drug delivery and imaging platforms are of growing interest, the potential toxicity of these nanoparticles in the CNS is a concern. High levels of iron have been found in autopsy section from patients with neurodegenerative disease, for example, Alzheimer's disease, Huntington's disease, and Parkinson's disease, ${ }^{5,6}$ leading to the suggestion that elevated iron concentrations within the brain contribute to the development of neurodegenerative disease. However, it is not clear whether the imbalanced iron homeostasis in the brain is the cause of the disease state or the consequence of the disease process. ${ }^{7}$ Similar arguments can be made about the current debate concerning beta amyloid plaques being an important component of Alzheimer's disease or a late stage disease marker. Such issues are inherently difficult to assess.

The use of IONPs to track and monitor grafted stem cells during stroke and traumatic brain injury and image various inflammatory CNS pathologies in both preclinical and clinical trials speaks to the general safety profile. ${ }^{8,9}$ However, the amount of IONP actually delivered to the brain in the imaging applications above is much reduced in comparison to applications involving CNS drug delivery. Ultimately, toxicity will likely be dependent on both the amount of IONP in the brain and the composition of the IONP. Maghemite $\left(\mathrm{Fe}_{2} \mathrm{O}_{3}\right)$ and magnetite $\left(\mathrm{Fe}_{3} \mathrm{O}_{4}\right)$ are the most common core components of IONPs. Exposure to these core components could lead to the production of free radicals via Fenton and/or Haber-Weiss reactions. ${ }^{10}$ Oxidative toxicity associated with both maghemite and magnetite species of IONPs has been reported. ${ }^{11,12}$ It has been shown that the generation of reactive oxygen species and increased oxidative stress contribute to IONP toxicity in murine macrophages. ${ }^{13}$ However, little is known about potential toxicity of IONPs in brain-specific cells. Studies by Rivet and colleagues reported neuronal cell death following exposure to polydimethylamine functionalized IONPs; however, other surface coatings of the IONPs, such as aminosilane and dextran coating, produced minimal toxicity. ${ }^{14}$ Potential toxicity in other CNS cells, such as astroctyes and cerebral vascular endothelial cells, have not been evaluated. Information concerning IONP toxicity in astrocytes is of particular interest given the role of astrocytes in propagating inflammatory signals within the brain. ${ }^{15}$ Furthermore, the variety of cell types found in the brain and the diversity of chemical constructs of IONPs make it difficult to translate toxicity data obtained in one particular cell type with a specific IONP composition.

Several surface modification methods using different silane constructs have been explored. ${ }^{16,17}$ However, little is known about the effect of surface charge on biocompatibility of aminosilane-coated IONPs (AmS-IONPs) for brain-related drug delivery applications. To this end, the aim of this study was to investigate and compare the cytotoxicity and uptake profile of positive- and negative-charged AmS-IONPs in CNS-relevant cell culture models (ie, brain endothelial cells, neurons, and astrocytes). It was hypothesized that toxicity would be a function of cellular accumulation and the modifications that enhanced uptake, such as changes in surface charge or the application of a magnetic field, would directly affect toxicity. To test this we examined cellular accumulation and toxicity of AmS-IONPs with positive surface charges due to the presence of amine functional groups and $\mathrm{COOH}-\mathrm{AmS}-\mathrm{IONPs}$ with negative surface charges due to $\mathrm{COOH}$ functional groups in the presence and absence of a magnetic field.

\section{Material and methods Materials}

All reagents were purchased from Sigma-Aldrich (St Louis, MO, USA) and cell culture reagents from Invitrogen Canada Inc (Burlington, ON, Canada) unless otherwise specified.

\section{Nanoparticle synthesis and characterization}

Iron-oxide nanoparticles were prepared under mild conditions of solvent and temperature as previously described. ${ }^{18}$ Aminosilane coating of the IONPs was performed by rapidly adding 3-aminopropyltriethoxysilane (APTES, $17 \mathrm{mmol}$ ) to the IONPs in a reaction vessel and stirring continuously overnight at room temperature. 
The crude product was purified by dialysis (molecular weight cut-off 30,000) against deionzed (DI) water over 48 hours and was stored in DI water until further studies or chemical modifications. The resulting AmS-IONPs had a magnetite core and aminosilane outer shell with free amine functional groups. The COOH-AmS-IONPs were prepared by one additional step in which bromoacetic acid (BAA, dissolved in DI water) was titrated dropwise into the AmS-IONPs dispersion, followed by mechanical stirring at room temperature overnight. This resulted in the displacement of bromide groups on the $\alpha$-carbon of BAA by amine functional groups of AmS-IONPs. Excess BAA was then removed by dialysis to yield $\mathrm{COOH}-\mathrm{AmS}$-IONPs with negatively charged surface properties. Both AmS-IONP and $\mathrm{COOH}-\mathrm{AmS}$-IONP compositions formed colloidal dispersions in water that were stable over at least a 2-month period. Hydrodynamic diameter and zeta potential of the IONP dispersions were measured using a Nano-partica SZ-100 series instrument (Horiba Scientific, Kyoto, Japan) with a diode-pumped solid-state (DPSS) $532 \mathrm{~nm}, 10 \mathrm{~mW}$ Class 1 laser, real refractive index of 2.42. The medium viscosity at $20^{\circ} \mathrm{C}$ was $1.002 \mathrm{cp}$. The dielectric constant was 80.100. The scattering angle in both cases was set at $90^{\circ}$.

\section{Cell culture}

A mouse brain-derived microvessel endothelial cell line, bEnd.3 (American type tissue culture collection, Manassas, VA), was used as a cell culture model of the blood-brain barrier (BBB). The bEnd.3 cells (passage number 15-30) were cultured in Dulbecco's Modified Eagle Medium (DMEM) (Hyclone, Logan, UT) supplemented with 10\% heat-inactivated fetal bovine serum (FBS; Hyclone), $50 \mathrm{U} /$ $\mathrm{mL}$ penicillin and streptomycin (MP Biomedicals, Solon, $\mathrm{OH}, \mathrm{USA}$ ) at $37^{\circ} \mathrm{C}$ and $5 \% \mathrm{CO}_{2}$. Cells were expanded in $\mathrm{T}-75$ tissue culture flasks and seeded at $2 \times 10^{4}$ cells per $\mathrm{cm}^{2}$ on six- or twelve-well plates for uptake and cytotoxicity studies, respectively. Culture medium was changed every 2 days. All experiments were performed on confluent monolayers (typically 4-5 days post seeding). Primary neurons and astrocytes were isolated from cortices of wild-type mice (CD1 neuron and C57BL6 astrocyte) as described previously. ${ }^{19}$ Isolated neurons were plated at 15,000 cells $/ \mathrm{cm}^{2}$ on six- or twelve-well plates coated with poly-D-lysine with neurobasal media supplemented with B-27. Astrocytes were seeded at 50,000 cells $/ \mathrm{cm}^{2}$ on six- or twelve-well plates in DMEMF12 media containing 10\% FBS. Neurons were used between 11 and 15 days in culture, while astrocytes were used between 7 and 15 days in culture.

\section{Cellular uptake of IONP compositions}

Confluent monolayers of bEnd.3 cells grown on sixwell culture plates (Costar, Lowell, MA, USA) were treated with culture media containing either positively or negatively charged aminosilane-coated IONP compositions $(1 \mu \mathrm{g} / \mathrm{mL}-50 \mu \mathrm{g} / \mathrm{mL}$ of $\mathrm{Fe})$. After treatment with IONPs, cells were placed in a humidified $\mathrm{CO}_{2}$ incubator maintained at $37^{\circ} \mathrm{C}$. At various time points ( $0-5$ hours), the IONP solutions were removed and the cell monolayers were washed $3 \mathrm{X}$ with ice cold phosphate-buffered saline (PBS) to remove unbound nanoparticles. Cells were lysed by the addition of $500 \mu \mathrm{L}$ of $0.2 \mathrm{~N} \mathrm{NaOH}$, and IONP content was determined based on the ferrozine assay described below. Cellular accumulation was examined in both the presence and absence of a static magnetic field created by placing the cells over a platform containing cylindrical rare earth magnets (19 $\mathrm{mm}$ diameter, $3 \mathrm{~mm}$ height) (Lee Valley, Winnipeg, MB, Canada). Cells remained in the magnetic field for the duration of the experiment. Cellular accumulation in astrocyte and neuronal cell cultures was performed under similar conditions except that the $\mathrm{COOH}-\mathrm{AmS}-\mathrm{IONP}$ accumulation in primary neuronal cultures was obtained by subtracting the amount of COOH-AmS-IONP adsorbed to the poly-D-lysine-coated plates without cells. This was necessary to account for the potential interaction of COOH-AmS-IONPs with the polyD-lysine coating on the plates.

\section{Cell viability studies}

Cells were grown in twelve-well plates (Costar) and treated with various concentrations $(0.1-224 \mu \mathrm{g} / \mathrm{mL})$ of AmS-IONPs or COOH-AmS-IONPs for 24 hours at $37^{\circ} \mathrm{C}$. Cell viability was determined using the 3-(4,5-dimethylthiazol-2-yl)-2,5diphenyltetrazolium bromide (MTT) assay as previously reported. ${ }^{18}$ Briefly, MTT dye $(5 \mathrm{mg} / \mathrm{mL}$ in PBS) was added to each well and incubated for 3 hours at $37^{\circ} \mathrm{C}$. Cells were solubilized in dimethylsulfoxide, and the formazan product resulting from mitochondrial metabolism in viable cells was measured by absorbance at $567 \mathrm{~nm}$ using a Synergy HT plate reader (BioTek, Winooski, VT, USA). Absorbance readings following IONP exposure with and without magnetic field to that in cells receiving only media (control) were compared. Cell viability was expressed as a percentage of the absorbance levels observed in the control cells.

\section{Analytical assay for measuring IONPs}

Quantitative determination of IONP content in cell and media samples was performed using the ferrozine assay. As the ferrozine assay is an absorbance-based assay for determining 
soluble iron concentrations, IONPs in the cell lysate and media samples were first solubilized by adding $500 \mu \mathrm{L}$ of concentrated $\mathrm{HCl}(\sim 12 \mathrm{M})$ to $500 \mu \mathrm{L}$ of cell lysate or media samples. This mixture was incubated for 1 hour at room temperature with gentle shaking and then neutralized with $500 \mu \mathrm{L}$ of $12 \mathrm{M} \mathrm{NaOH}$. Once the samples were neutralized, $120 \mu \mathrm{L}$ of hydroxylamine hydrochloride $(2.8 \mathrm{M})$ in $4 \mathrm{M} \mathrm{HCl}$ was added and the samples incubated for 60 minutes at room temperature with gentle shaking. Following this incubation, $50 \mu \mathrm{L}$ of $10 \mathrm{M}$ ammonium acetate solution ( $\mathrm{pH} 9.5$ ) and $300 \mu \mathrm{L}$ of $10 \mathrm{mM}$ ferrozine in $0.1 \mathrm{M}$ ammonium acetate solution was added to each sample. Absorbance was measured at $562 \mathrm{~nm}$ using a Synergy HT plate reader. Quantitative assessment of IONP concentration was based on a standard curve prepared using 1000 ppm iron atomic absorption standard (Fisher Scientific, Ottawa, ON, Canada). Samples from the cell lysates were normalized for protein content using the bicinchoninic acid assay kit (Pierce, Rockford, IL, USA).

\section{Electron microscopy}

The cellular localization of AmS-IONP and COOHAmS-IONP compositions was examined using transmission electron microscopy. For these studies, bEnd.3 cells were incubated with IONPs at a $50 \mu \mathrm{g} / \mathrm{mL}$ concentration in media for 2 hours. After incubation cells were washed $3 \mathrm{X}$ with PBS and collected using 0.25\% trypsin EDTA (Hyclone). After centrifugation the cell pellets where fixed in $3 \%$ glutaraldehyde in $0.1 \mathrm{M}$ phosphate buffer ( $\mathrm{pH} 7.3$ ), followed by postfixation in $1 \%$ osmium tetroxide in $0.1 \mathrm{M}$ phosphate buffer ( $\mathrm{pH} 7.3$ ). Cells were then dehydrated and embedded in Epon 812 using standard techniques. ${ }^{20}$ Thin sections were stained with uranyl acetate and lead citrate, viewed, and photographed in a Philips CM 10 electron microscope
(FEI, Hillsboro, OR, USA). In order to eliminate observer bias, sections were examined without foreknowledge of their source.

\section{Statistical analysis}

All data were expressed as mean \pm standard error of the mean. All values were obtained from at least three independent experiments. Statistical significance was evaluated using one-way analysis of variance followed by post hoc comparison of the means using the Fisher's least significant difference test.

\section{Results \\ Physicochemical characterization of IONPs}

The properties and schematic representation of the IONPs used in the present study are provided in Figure 1. The uncoated IONP form a quasi-spherical (polyhedral) nanoparticle, ${ }^{18}$ which is maintained following aminosilane coating. The average hydrodynamic size of both the AmS-IONP and COOH-AmS-IONP compositions were approximately $27 \mathrm{~nm}$ as determined using dynamic light scattering in water (Figure 1). While the sizes of the IONPs were similar, surface charge characteristics were substantially different, with the AmS-IONPs having a zeta potential of $+23.9 \mathrm{mV}$ compared to the $-17.0 \mathrm{mV}$ observed in the COOH-AmS-IONP compositions.

\section{Cytotoxicity of AmS-IONPs}

The MTT assay, which measures mitochondrial metabolic activity, is a common method used to measure toxicity mediated by nanoparticles. In these experiments the viability of bEnd. 3 cells, mouse primary astrocytes, and neurons

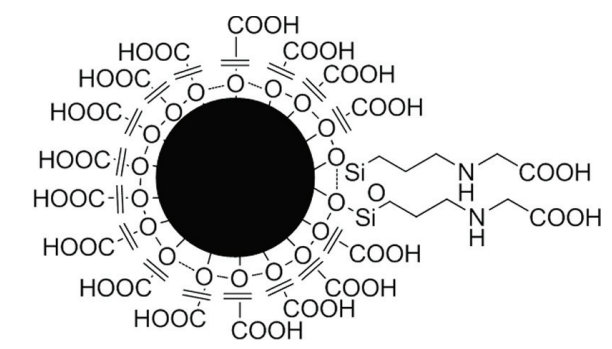

$\mathrm{COOH}-\mathrm{AmS}-\mathrm{IONP}$

$-17.0 \pm 3.9 \mathrm{mV}$

$26.8 \pm 8.9 \mathrm{~nm}$

Figure I Schematic of positively charged (AmS-IONPs) and negatively charged (COOH-AmS-IONPs) nanoparticles and their physical properties.

Notes: Measurements were performed in triplicate samples using a Nano-partica SZ- 100 series instrument from Horiba. Values represent the mean \pm standard error of the mean $(n=3)$.

Abbreviation: AmS-IONPs, aminosilane-coated iron oxide nanoparticles. 
A

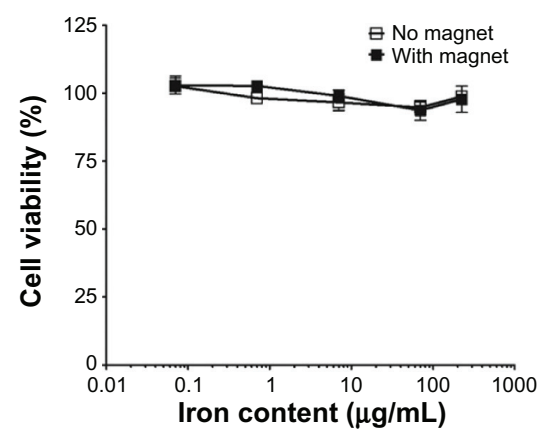

B

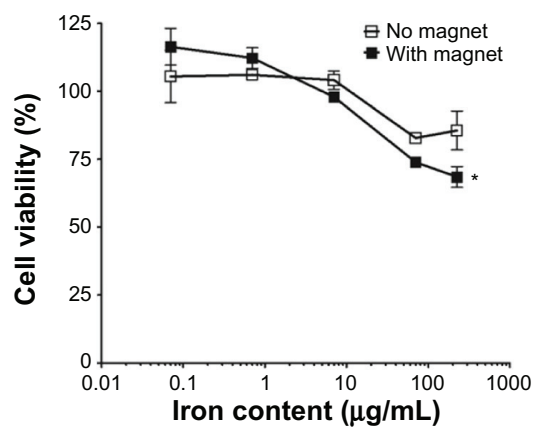

C

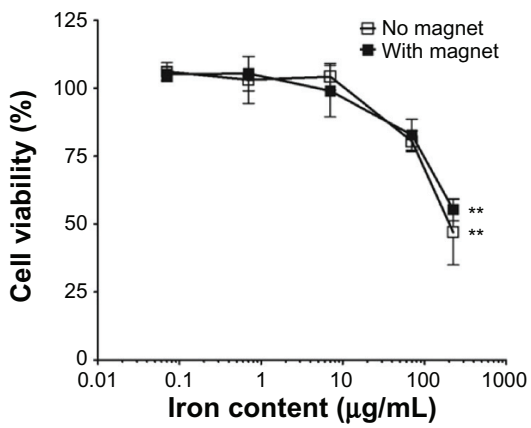

Figure 2 bEnd.3 cell (A), astrocyte (B), and neuron (C) viability following a 24-hour exposure to various concentrations of AmS-IONPs.

Notes: Iron content was used to normalize the concentration of various formulated IONPs. Values represent the mean \pm standard error of the mean of three samples per treatment group. *Indicates $P<0.05$ compared to control; **indicates $P<0.01$.

Abbreviation: AmS-IONPs, aminosilane-coated iron oxide nanoparticles.

was evaluated after 24 hours incubation in the absence and presence of a magnetic field (Figure 2). No significant toxicity was observed in bEnd. 3 cells at any concentration examined. Significant toxicity resulting in a $25 \%$ reduction in cell viability was observed in astrocytes at the highest concentration $(224 \mu \mathrm{g} / \mathrm{mL})$ of AmS-IONPs examined but only in the presence of a magnetic field (Figure 2). Neurons displayed an even greater decrease in viability (approximately 50\%) following exposure to $224 \mu \mathrm{g} / \mathrm{mL}$ AmSIONPs, and this was observed with or without the presence of a magnetic field (Figure 2).

\section{Cytotoxicity of $\mathrm{COOH}-\mathrm{AmS}-\mathrm{IONPs}$}

While there was no toxicity observed in the endothelial cell culture model at any concentration examined, exposure of $\mathrm{COOH}-\mathrm{AmS}-\mathrm{IONPs}$ exhibited significant toxicity at high concentrations (ie, $>100 \mu \mathrm{g} / \mathrm{mL}$ ) for astrocytes and neurons (Figure 3). Significant decreases in cell viability in astrocyte cultures were observed at concentrations of COOH-AmS-IONP of $100 \mu \mathrm{g} / \mathrm{mL}$ compared with the control group $(P<0.001)$. Further decreases in viability were observed at concentrations of $150 \mu \mathrm{g} / \mathrm{mL}$ with only $65 \%$ of astrocytes being viable after 24 hours of exposure to $\mathrm{COOH}-\mathrm{AmS}-\mathrm{IONP}$. The presence of a magnetic field increased cytotoxicity to the COOH-AmS-IONP at higher concentrations (ie, $>100 \mu \mathrm{g} / \mathrm{mL}$ ) in astrocytes (Figure 3). In contrast, negatively charged COOH-AmS-IONP produced no toxicity in cultured neurons at concentrations below $150 \mu \mathrm{g} / \mathrm{mL}$ in the absence of magnetic field. However, at concentrations above this level an approximately $25 \%$ loss of viability was observed. Statistically significant decreases in viability were observed following application of a magnetic field at the $100 \mu \mathrm{g} / \mathrm{mL}$ concentration of $\mathrm{COOH}-$ AmS-IONPs compared to the control group; however, there was no significant difference in viability without a magnetic field at the same concentration.
A

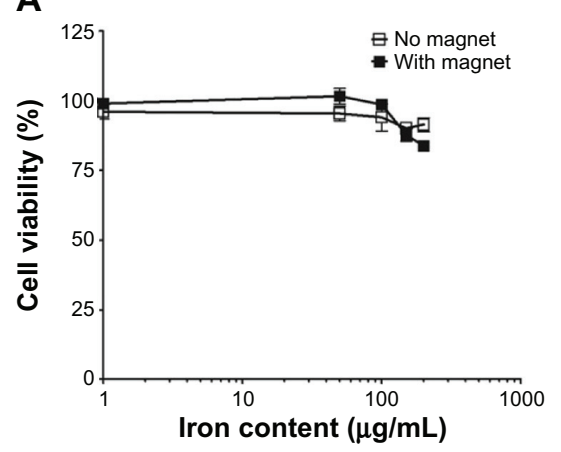

B

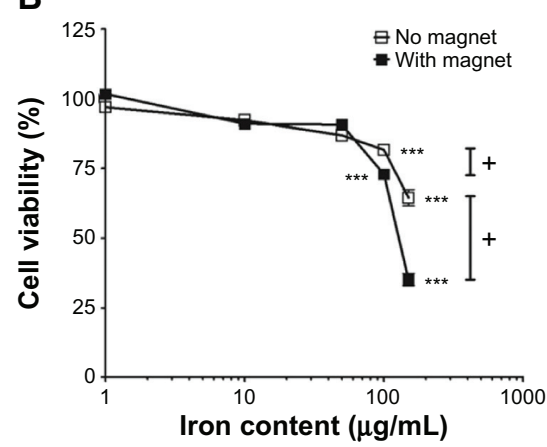

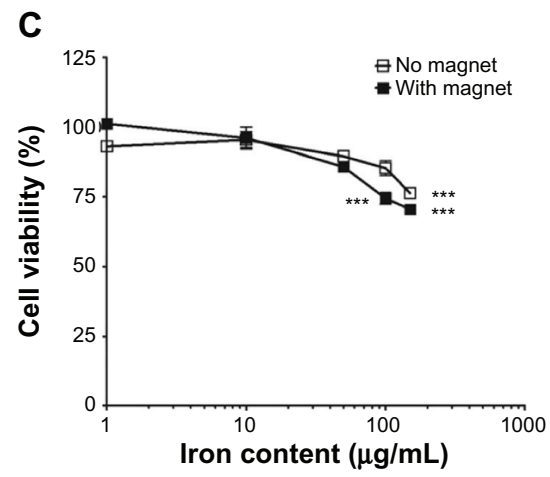

Figure 3 MTT assay of COOH-AmS-IONPs to bEnd.3 cells (A), astrocytes (B), and neurons (C).

Notes: Iron content was used to normalize the concentration of various formulated IONPs. Values represent the mean \pm standard error of the mean of three samples per treatment group. ${ }^{* * *}$ Indicates $P<0.001$ compared to control; ${ }^{+}$indicates $P<0.05$ compared to the same concentration without a magnet. Abbreviations: MTT, 3-(4,5-dimethylthiazol-2-yl)-2,5-diphenyltetrazolium bromide; AmS-IONPs, aminosilane-coated iron oxide nanoparticles. 


\section{Cellular uptake of AmS-IONPs and $\mathrm{COOH}-\mathrm{AmS}-\mathrm{IONPS}$}

The initial parameters for examining cellular accumulation of the aminosilane-coated IONPs were determined in bEnd. 3 cell monolayers. Accumulation of AmS-IONPs in bEnd.3 cells was both time and concentration dependent, with maximal uptake observed at concentrations of $10 \mu \mathrm{g} / \mathrm{mL}$ or greater and at the 5 hour time period (Figure 4A). As accumulation was maximal at concentrations of $10 \mu \mathrm{g} / \mathrm{mL}$ or greater at all time points examined, subsequent accumulation studies were performed at concentrations at or below $10 \mu \mathrm{g} / \mathrm{mL}$. Cellular accumulation of AmS-IONPs was also dependent on temperature, with much higher accumulation observed at $37^{\circ} \mathrm{C}$ compared to $4^{\circ} \mathrm{C}$ (Figure $4 \mathrm{~B}$ and $\mathrm{C}$ ). Application of a magnetic field enhanced accumulation of AmS-IONPs at all concentrations examined and at both $37^{\circ} \mathrm{C}$ and $4{ }^{\circ} \mathrm{C}$ (Figure 4B and C). The uptake difference between $37^{\circ} \mathrm{C}$ and $4^{\circ} \mathrm{C}$ upon exposure to a magnetic field was also increased at various concentrations.

A similar cellular accumulation profile for AmS-IONP was observed in cultured bEnd.3 and primary cultured astrocytes and neurons (Figure 5). Application of a magnetic field enhanced the amount of cell-associated AmS-IONPs at all concentrations examined. The effects of a magnetic field were most apparent in the $5 \mu \mathrm{g} / \mathrm{mL}$ treatment group in bEnd. 3 cells (Figure 5A). In contrast, the effects of a magnetic field were most apparent in the $2.5 \mu \mathrm{g} / \mathrm{mL}$ treatment group for astrocytes and $10 \mu \mathrm{g} / \mathrm{mL}$ treatment group for neurons (Figure 5B and C). There was a threefold increase in cellular accumulation of AmSIONPs in astrocytes compared to neurons. The rank order of accumulation with the AmS-IONPs was astrocytes $>$ endothelial cells $>$ neurons.
Compared to the AmS-IONP uptake profile, cellular accumulation of $\mathrm{COOH}-\mathrm{AmS}-\mathrm{IONPs}$ was significantly reduced at all concentrations examined. In contrast to the AmS-IONP compositions, which displayed concentrationdependent uptake, the accumulation of COOH-AmS-IONPs was similar at all concentrations examined. The negatively charged $\mathrm{COOH}-\mathrm{AmS}$-IONPs showed the same low uptake profile in both neurons and astrocytes, with less than $5 \mathrm{ng}$ of iron per $\mu \mathrm{g}$ of protein accumulation in the cells. Magnetic field exposure increased uptake of COOH-AmS-IONPs to $15 \mathrm{ng}$ of iron per $\mu \mathrm{g}$ of protein. Electron micrographs of bEnd.3 cells further support the differences in cellular uptake of the various IONP compositions (Figure 6). While bEnd.3 cells exposed to AmS-IONPs displayed many intracellular vesicles containing nanoparticles, cells exposed to COOH-IONPs had substantially fewer intracellular organelles containing nanoparticles (Figure 6).

\section{Discussion}

This study is concerned with the biocompatibility of AmSIONPs formulations and the influence that surface charge has on both cellular accumulation and toxicity in cells within the brain. While additional nanoparticle modifications will undoubtedly be required for enhancing brain delivery and drug release, AmS- and COOH-AmS-IONPs represent the building blocks from which a variety of functionalized IONP compositions will be created. Thus, establishing the cellular uptake and toxicity of AmS- and COOH-AmS-IONPs represents a baseline from which additional surface modifications can be evaluated for potential CNS drug delivery applications. As the IONPs in the present study have the same core and aminosilane coating but are at two different ends of the surface charge spectrum, these studies provide an
A

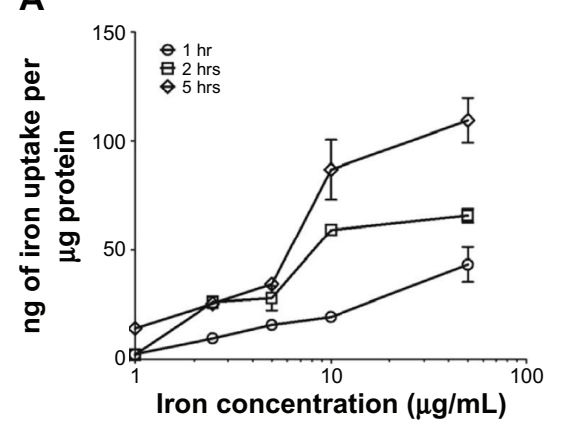

B

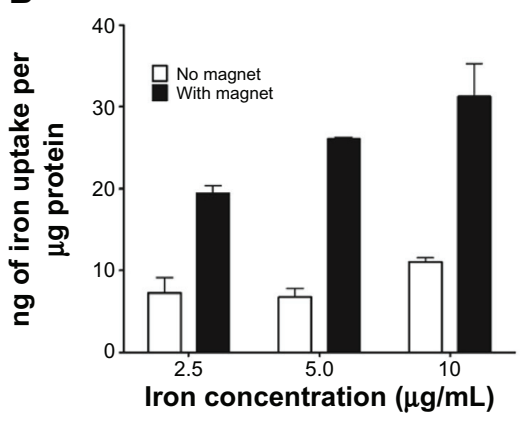

C

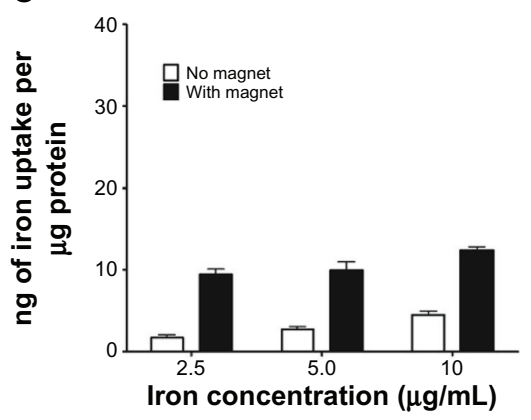

Figure 4 Cellular uptake of AmS-IONPs in bEnd.3 cells. Amount of iron accumulation in the cells normalized to protein in time- and concentration-dependent manner (A). The cells were incubated with AmS-IONPs for 1.5 hours at $37^{\circ} \mathrm{C}(\mathrm{B})$ or $4^{\circ} \mathrm{C}(\mathrm{C})$.

Note: Values represent the mean \pm standard error of the mean of three samples per treatment group.

Abbreviation: AmS-IONPs, aminosilane-coated iron oxide nanoparticles. 

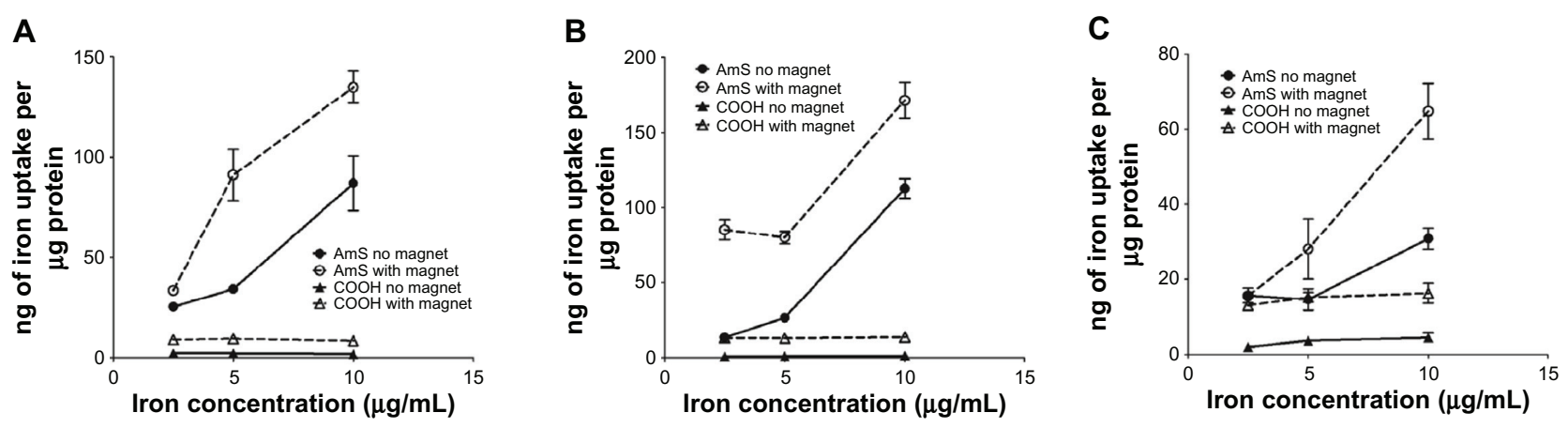

Figure 5 Cellular uptake of AmS-IONPs and COOH-AmS-IONPs in bEnd.3 cells (A), astrocytes (B), and neurons $(\mathbf{C})$ at $37^{\circ} \mathrm{C}$.

Note: Values represent the mean \pm standard error of the mean of three samples per treatment group.

Abbreviation: AmS-IONPs, aminosilane-coated iron oxide nanoparticles.

excellent opportunity to probe the influence of surface charge on cell accumulation and toxicity in brain-relevant cells.

There are several different strategies that have been examined for enhancing BBB permeability of nanoparticles. One involves various surface modifications using specific ligands to overcome BBB by receptormediated transcytosis. ${ }^{21,22}$ For example, apolipoprotein E-modified human serum albumin nanoparticles cross the BBB via low-density lipoprotein-mediated endocytosis. ${ }^{23}$ Another strategy involves magnetic targeting of long circulating magnetic nanoparticles and disruption of the BBB. ${ }^{24}$ For example, magnetic targeting and the BBB disruption by focused ultrasound synergistically enhanced delivery of magnetic nanoparticles into the brain. ${ }^{25} \mathrm{We}$ demonstrated that the positively charged AmS-IONPs favor an endocytosis pathway and therefore may be useful starting material for combining with ligands to enhance the transcytosis route. In contrast, the negatively charged COOH-AmS-IONPs showed minimal uptake by cells, so these particles, and derivatives thereof, may be good
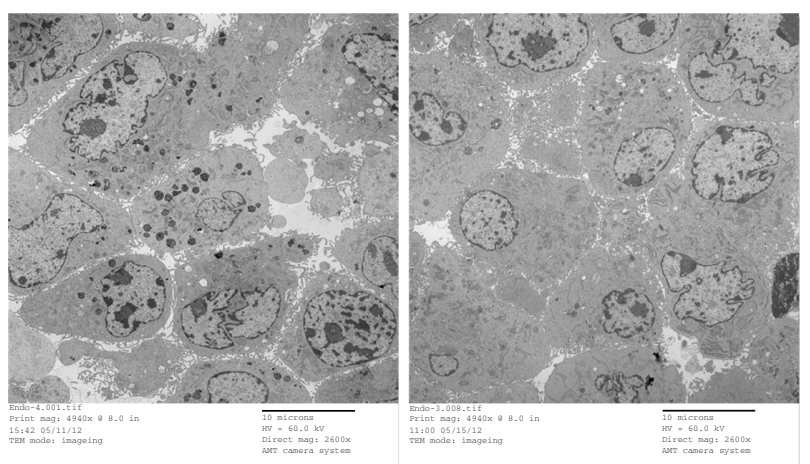

Figure 6 TEM images of bEnd. 3 cells that were incubated with AmS-IONPs (left) or $\mathrm{COOH}-A m S-I O N P s$ (right).

Note: Electron-dense particles are visible in intracellular vesicles.

Abbreviations: TEM, transmission electron microscopy; AmS-IONPs, aminosilanecoated iron oxide nanoparticles. candidates for magnetic targeting through a transiently disrupted BBB.

The results of the present study indicate that both AmS- and COOH-AmS-IONPs were well tolerated by neurons, astrocytes, and brain microvessel endothelial cells. Toxicity, when present, was only observed at relatively high concentrations. This is different from other metal-based nanoparticles, including zinc and titanium oxide nanoparticles that have substantial toxicity in neurons and astrocytes. ${ }^{26-28}$ Compared to these other metal nanoparticles, the IONP-based compositions used in the present study appear to have good biocompatibility with concentrations required to produce toxicity being rather large and not likely to be obtained in vivo or in clinical applications. ${ }^{11,29}$

We had hypothesized that the extent of nanoparticle accumulation in cells would have important implications in the extent of potential toxicity produced. In the current study there was an approximately threefold increase in the accumulation of AmS-IONPs in astrocytes and bEnd. 3 cells compared to neurons. However, of the three cell types examined, neurons showed the greatest toxicity to the AmS-IONP compositions. Conversely, cellular accumulation of $\mathrm{COOH}-\mathrm{AmS}$-IONPs was substantially less than that observed with AmS-IONPs in astrocytes and yet the COOH-AmS-IONPs produced greater toxicity than the AmS-IONPs. Taken together, these observations suggest it may be the surface coating that is the primary factor in determining the toxicity response observed.

In support of the surface coating and its influence on toxicity, it has been noted that cationic hydrogels produce significant decreases in neuron cell viability, whereas neutral hydrogels show no toxicity. ${ }^{30}$ This is consistent with the findings in the present study that positively charged surface coatings affect neuronal function to a greater extent than the negatively charged nanoparticles. While the exact mechanism 
explaining the toxicity observed with high concentrations of negatively charged COOH-AmS-IONPs in astrocytes is unknown, it may be related to the potential responses to reactive oxygen species in astrocytes and neurons. Studies using a hippocampal slice culture model reported astrocytes exhibited a significantly higher sensitivity to reactive oxygen species than neurons. ${ }^{31}$ The recent studies of Haase and colleagues support this possibility as astrocytes were found to be more sensitive to silver oxide nanoparticles compared to neurons due to the oxidative stress responses produced in the astrocytes. ${ }^{32}$

Previous studies using a human neuroblastoma cell line reported $60 \%$ cell viability at a $2.25 \mathrm{mM}$ concentration of AmS-IONPs. ${ }^{33}$ The toxicity was correlated with the upregulation of genes associated with cell growth arrest and apoptosis in the case of AmS-IONPs, while genes associated with cell proliferation response were upregulated upon negatively charged IONPs due to its reactive oxygen species generation properties. ${ }^{33}$ The present study used primary cultured neurons and astrocytes to more accurately reflect potential toxicity within the brain. We found that both AmS- and COOH-AmS-IONPs were well tolerated in primary neuron and astrocyte preparations, with toxicity observed only at high concentrations. Studies to identify potential cellular pathways influenced by IONP exposure and potential cellspecific differences are currently ongoing.

As the brain endothelial cells that form the BBB have restricted paracellular permeability under normal conditions, the cellular accumulation of the AmS- and COOH-AmSIONPs has important implications in the potential passage of IONPs across the BBB. Based on the present study, there is a clear preference for positively charged AmS-IONPs in regards to both attachment to the plasma membrane and vesicular internalization within brain endothelial cells. The positively charged AmS-IONPs displayed a higher rate of endocytic activity, which was concentration dependent. In this regard our results are in accordance with a previous report conducted using various mammalian cell lines. ${ }^{34}$ The present studies showing increased cellular accumulation of the positively charged AmS-IONP are consistent with the enhanced adsorptive endocytosis observed following cationization of albumin in brain endothelial cells. ${ }^{35}$ The negatively charged COOH-AmS-IONPs were less likely to interact with the cell membrane, resulting in decreased uptake and a lack of concentration dependency. Such characteristics are consistent with nonspecific, fluid-phase, endocytosis mechanisms for the COOH-AmS-IONPs. Applying a magnetic field resulted in increased amounts of
IONPs associated with the cells. This was expected as in the presence of a magnetic field the IONPs dispersed in the media will move toward a high-gradient magnetic field at the bottom of the culture plate, increasing the interactions with the cells. However, even in the presence of a magnetic field the cellular uptake of COOH-AmS-IONPs was fourfold less than AmS-IONPs in neurons and tenfold less in bEnd. 3 cells and astrocytes.

Nanoparticles in contact with cells can either be adsorbed on the cellular membranes or internalized into membrane-bounded endocytic compartments. ${ }^{36}$ Uptake studies in bEnd. 3 cells performed both at $4^{\circ} \mathrm{C}$ and at $37^{\circ} \mathrm{C}$ allowed us to distinguish between the adsorbed and internalized AmS-IONPs. Because endocytosis processes are strongly temperature dependent and internalization of NPs was inhibited at $4{ }^{\circ} \mathrm{C},{ }^{37}$ the amount of iron detected at $4{ }^{\circ} \mathrm{C}$ represents AmS-IONPs adsorbed on the plasma membrane of the cell. Furthermore, the difference in the AmS-IONP uptake profile at $37^{\circ} \mathrm{C}$ and $4^{\circ} \mathrm{C}$ represents internalized NPs. Similar temperature-dependent uptake of IONPs has been reported in astrocytes. ${ }^{37}$ Of note, the presence of a magnetic field greatly increased both intracellular and extracellular accumulation of IONPs, suggesting a nonspecific AmSIONP interaction with the cell that may be exploited for drug delivery purpose. Such effects of a magnetic field on cellular accumulation of IONPs have been reported in other cells and are postulated to be a result of the physical pulling of AmS-IONPs toward cell membranes down the magnetic gradient. ${ }^{38}$ Studies to determine optimal magnetic field strength for both AmS-IONPs and COOH-AmS-IONPs are currently ongoing.

\section{Conclusion}

This study evaluated the toxicity and cellular accumulation of differently charged aminosilane-coated IONPs in brain endothelial cells, neurons, and astrocytes. There was no toxicity observed with either the positively charged AmS-IONPs or the negatively charged COOH-AmS-IONPs in cultured brain microvessel endothelial cells. At high concentrations neurons displayed toxicity to the positively charged AmSIONPs and the astrocytes appeared more vulnerable to the negatively charged $\mathrm{COOH}-\mathrm{AmS}-\mathrm{IONPs}$. The IONP toxicity did not correlate with the magnitude of accumulation as the $\mathrm{COOH}-\mathrm{AmS}$-IONPs had the lowest accumulation in all cell types but caused greater toxicity in astrocytes than the AmSIONP compositions. This suggests toxicity is dependent on surface coating more than the IONP core. AmS-IONPs displayed the highest cell accumulation in all cell types tested. 
Application of a magnetic field had a minimal impact on the cytotoxicity but significantly enhanced uptake of both IONP formulations in all cell types examined. These studies establish the baseline parameters for aminosilane-coated IONP uptake and biocompatibility and will help facilitate the design of more complex IONP compositions for CNS drug delivery applications.

\section{Acknowledgments}

This research was supported by grants from the Manitoba Medical Science Foundation, Dr Paul HT Thorlakson Foundation, Manitoba Health Research Council, and Natural Sciences and Engineering Research Council of Canada.

\section{Disclosure}

The authors report no conflicts of interest in this work.

\section{References}

1. Moraes L, Vasconcelos-Dos-Santos A, Santana FC, et al. Neuroprotective effects and magnetic resonance imaging of mesenchymal stem cells labeled with SPION in a rat model of Huntington's disease. Stem cell Res. 2012;9(2):143-155.

2. Maier-Hauff K, Ulrich F, Nestler D, et al. Efficacy and safety of intratumoral thermotherapy using magnetic iron-oxide nanoparticles combined with external beam radiotherapy on patients with recurrent glioblastoma multiforme. J Neurooncol. 2011;103(2):317-324.

3. Kenzaoui BH, Bernasconi CC, Hofmann H, Juillerat-Jeanneret L. Evaluation of uptake and transport of ultrasmall superparamagnetic iron oxide nanoparticles by human brain-derived endothelial cells. Nanomedicine (Lond). 2012;7(1):39-53.

4. Bae JE, Huh MI, Ryu BK, et al. The effect of static magnetic fields on the aggregation and cytotoxicity of magnetic nanoparticles. Biomaterials. 2011;32(35):9401-9414.

5. Prohaska R, Sibon OC, Rudnicki DD, et al. Brain, blood, and iron: perspectives on the roles of erythrocytes and iron in neurodegeneration. Neurobiol Dis. 2012;46(3):607-624.

6. Zheng W, Monnot AD. Regulation of brain iron and copper homeostasis by brain barrier systems: implication in neurodegenerative diseases. Pharmacol Ther. 2012;133(2):177-188.

7. Batista-Nascimento L, Pimentel C, Menezes RA, Rodrigues-Pousada C. Iron and neurodegeneration: from cellular homeostasis to disease. Oxid Med Cell Longev. 2012;2012:128647.

8. Kubinova S, Sykova E. Nanotechnology for treatment of stroke and spinal cord injury. Nanomedicine (Lond). 2010;5(1):99-108.

9. Stoll G, Bendszus M. Imaging of inflammation in the peripheral and central nervous system by magnetic resonance imaging. Neuroscience. 2009;158(3):1151-1160.

10. Voinov MA, Sosa Pagan JO, Morrison E, Smirnova TI, Smirnov AI. Surface-mediated production of hydroxyl radicals as a mechanism of iron oxide nanoparticle biotoxicity. J Am Chem Soc. 2011;133(1): 35-41.

11. Hanini A, Schmitt A, Kacem K, Chau F, Ammar S, Gavard J. Evaluation of iron oxide nanoparticle biocompatibility. Int $J$ Nanomedicine. 2011;6:787-794.

12. Ma P, Luo Q, Chen J, et al. Intraperitoneal injection of magnetic $\mathrm{Fe}(3) \mathrm{O}(4)$-nanoparticle induces hepatic and renal tissue injury via oxidative stress in mice. Int J Nanomedicine. 2012;7:4809-4818.

13. Naqvi S, Samim M, Abdin M, et al. Concentration-dependent toxicity of iron oxide nanoparticles mediated by increased oxidative stress. Int J Nanomedicine. 2010;5:983-989.
14. Rivet CJ, Yuan Y, Borca-Tasciuc DA, Gilbert RJ. Altering iron oxide nanoparticle surface properties induce cortical neuron cytotoxicity. Chem Res Toxicol. 2012;25(1):153-161.

15. Bernardi A, Frozza RL, Meneghetti A, et al. Indomethacin-loaded lipid-core nanocapsules reduce the damage triggered by Abeta 1-42 in Alzheimer's disease models. Int J Nanomedicine. 2012;7:4927-4942.

16. Hong SC, Lee JH, Lee J, et al. Subtle cytotoxicity and genotoxicity differences in superparamagnetic iron oxide nanoparticles coated with various functional groups. Int J Nanomedicine. 2011;6:3219-3231.

17. Galeotti F, Bertini F, Scavia G, Bolognesi A. A controlled approach to iron oxide nanoparticles functionalization for magnetic polymer brushes. J Colloid Interface. 2011;360(2):540-547.

18. Yathindranath V, Rebbouh L, Moore DF, Miller DW, van Lierop J, Hegmann T. A versatile method for the reductive, one-pot synthesis of bare, hydrophilic and hydrophobic magnetite nanoparticles. Adv Funct Mater. 2011;21(8):1457-1464.

19. Zamzow CR, Xiong W, Parkinson FE. Adenosine produced by neurons is metabolized to hypoxanthine by astrocytes. J Neurosci Res. 2008;86(15):3447-3455.

20. Luft JH. Improvements in epoxy resin embedding methods. J Biophys Biochem Cytol. 1961;9:409-414.

21. Wohlfart S, Gelperina S, Kreuter J. Transport of drugs across the blood-brain barrier by nanoparticles. J Control Release. 2012;161(2): 264-273.

22. Celia C, Cosco D, Paolino D, Fresta M. Nanoparticulate devices for brain drug delivery. Med Res Rev. 2010;31:716-756.

23. Wagner S, Zensi A, Wien SL, et al. Uptake mechanism of ApoE-modified nanoparticles on brain capillary endothelial cells as a blood-brain barrier model. PloS one. 2012;7(3): 32568.

24. Wankhede M, Bouras A, Kaluzova M, Hadjipanayis CG. Magnetic nanoparticles: an emerging technology for malignant brain tumor imaging and therapy. Expert Rev Clin Pharmacol. 2012;5(2):173-186.

25. Liu HL, Hua MY, Yang HW, et al. Magnetic resonance monitoring of focused ultrasound/magnetic nanoparticle targeting delivery of therapeutic agents to the brain. Proc Natl Acad Sci USA. 2010;107(34): $15205-15210$.

26. Hutter E, Boridy S, Labrecque S, et al. Microglial response to gold nanoparticles. ACS nano. 2010;4(5):2595-2606.

27. Zhao J, Xu L, Zhang T, Ren G, Yang Z. Influences of nanoparticle zinc oxide on acutely isolated rat hippocampal CA3 pyramidal neurons. Neurotoxicology. 2009;30(2):220-230.

28. Wang J, Chen C, Liu Y, et al. Potential neurological lesion after nasal instillation of $\mathrm{TiO}(2)$ nanoparticles in the anatase and rutile crystal phases. Toxicol Lett. 2008;183(1-3):72-80.

29. Chertok B, David AE, Yang VC. Polyethyleneimine-modified iron oxide nanoparticles for brain tumor drug delivery using magnetic targeting and intra-carotid administration. Biomaterials. 2010;31(24): $6317-6324$

30. Boridy S, Takahashi H, Akiyoshi K, Maysinger D. The binding of pullulan modified cholesteryl nanogels to Abeta oligomers and their suppression of cytotoxicity. Biomaterials. 2009;30(29):5583-5591.

31. Feeney CJ, Frantseva MV, Carlen PL, et al. Vulnerability of glial cells to hydrogen peroxide in cultured hippocampal slices. Brain Res. 2008;1198:1-15

32. Haase A, Rott S, Mantion A, et al. Effects of silver nanoparticles on primary mixed neural cell cultures: uptake, oxidative stress and acute calcium responses. Toxicol Sci. 2012;126(2):457-468.

33. Mahmoudi M, Laurent S, Shokrgozar MA, Hosseinkhani M. Toxicity evaluations of superparamagnetic iron oxide nanoparticles: cell "vision" versus physicochemical properties of nanoparticles. ACS Nano. 2011;5(9):7263-7276.

34. Zhu XM, Wang YX, Leung KC, et al. Enhanced cellular uptake of aminosilane-coated superparamagnetic iron oxide nanoparticles in mammalian cell lines. Int J Nanomedicine. 2012;7:953-964.

35. Kang YS, Pardridge WM. Brain delivery of biotin bound to a conjugate of neutral avidin and cationized human albumin. Pharm Res. 1994;11(9):1257-1264. 
36. Safi M, Courtois J, Seigneuret M, Conjeaud H, Berret JF. The effects of aggregation and protein corona on the cellular internalization of iron oxide nanoparticles. Biomaterials. 2011;32(35):9353-9363.

37. Lamkowsky MC, Geppert M, Schmidt MM, Dringen R. Magnetic field-induced acceleration of the accumulation of magnetic iron oxide nanoparticles by cultured brain astrocytes. J Biomed Mater Res A. 2012;100A:323-334.
38. Tresilwised N, Pithayanukul P, Mykhaylyk O, et al. Boosting oncolytic adenovirus potency with magnetic nanoparticles and magnetic force. Mol Pharm. 2010;7(4):1069-1089.

\section{Publish your work in this journal}

The International Journal of Nanomedicine is an international, peerreviewed journal focusing on the application of nanotechnology in diagnostics, therapeutics, and drug delivery systems throughout the biomedical field. This journal is indexed on PubMed Central, MedLine, CAS, SciSearch $\AA$, Current Contents ${ }^{\circledR} /$ Clinical Medicine,
Journal Citation Reports/Science Edition, EMBase, Scopus and the Elsevier Bibliographic databases. The manuscript management system is completely online and includes a very quick and fair peer-review system, which is all easy to use. Visit http://www.dovepress.com/ testimonials.php to read real quotes from published authors.

Submit your manuscript here: http://www.dovepress.com/international-journal-of-nanomedicine-journal 